\title{
Assessment of patient relevant outcomes in knee osteoarthritis patients using the Knee Injury and Osteoarthritis Outcome Score (KOOS) scale
}

\author{
VinodKumar MUGADA $1 *$ (D) , Pujitha KONDRU 2 (D), Sai Navya MANDA 2 (D), Mahalakshmi VEGI 2 (D), \\ Smruthi KAKADA 2 \\ 1 Department of Pharmacy Practice, Faculty of Pharmacy, Vignan Institute of Pharmaceutical Technology, Vizag, \\ India. \\ 2 Department of Pharmacy Practice, Pharm.D 5th year, Vignan Institute of Pharmaceutical Technology, Vizag, India. \\ * Corresponding Author. E-mail: mugadavinodkumar18@gmail.com (VK. M); Tel. +91-0891-251 1222.
}

Received: 15 April 2020 / Revised: 21 June 2020/ Accepted: 29 June 2020

ABSTRACT: Knee osteoarthritis causes physical, functional limitations and difficulty in performing activities of daily living and mobility. The study aimed to assess patient-relevant outcomes in knee osteoarthritis patients using the Knee Injury and Osteoarthritis Outcome Score (KOOS) scale. A descriptive cross-sectional study was conducted on 120 patients. KOOS scale contains five subscales: pain, symptom, activities of daily living, sports/recreation, and quality of life. Score zero indicates the worst possible knee problems, while score 100 indicates no knee problems. Non-parametric tests, multiple linear regression analysis, and correlation were calculated for the data. The level of significance was $\mathrm{p}<0.05$ and $\mathrm{p}<0.01$. The mean age group of patients was $54.58 \pm 10.73$ years. There was a statistically significant association observed between pain and disease duration $(\mathrm{p}=0.031)$; symptom and gender, comorbidities, and body mass index ( $\mathrm{p}=0.038,0.022$, and 0.017 , respectively); activities of daily living and knee surgery $(\mathrm{p}=0.043)$; sports $/$ recreation and knee involved, disease duration ( $\mathrm{p}=0.031,0.033$, respectively); and knee-related quality of life and gender $(\mathrm{p}=0.011)$. Knee surgery was an independent predictor for pain $(p=0.008)$ and activities of daily living $(p=0.008)$. There was a severe problem with sports/recreation in the patients. The knee-related quality of life was moderate. Knee surgery was found to be a strong independent predictor for pain and activities of daily living. However, socioeconomic status influenced the knee surgery in our patients.

KEYWORDS: Pain; Symptom; activities of daily living; sports; quality of life; KOOS; knee osteoarthritis.

\section{INTRODUCTION}

Knee osteoarthritis (KOA) affects the elderly and is the common cause of disability and reduced quality of life in the elderly. It creates physical and functional limitations. It causes difficulty in performing activities of daily living and mobility [1-3]. It is the 11th leading cause of years lived with disability and 38th highest contributor to disability-adjusted life years among 291 conditions [4]. 22\%-39\% of the Indian population suffers from osteoarthritis, and the prevalence of knee osteoarthritis accounts for $28.7 \%[4,5]$. There will be progressive joint dysfunction, and it makes daily living activities such as walking and climbing stairs difficult [6]. Self-reported outcome measures and performance-based tests evaluate knee-related pain and physical function [7]. However, self-reported questionnaires are easy to administer, economical, and does not discomfort patient physically. Also, self-reported questionnaires provide information about a person's experience during activities; however, performance-based tests show the ability to perform these activities [7].

Factors like age, obesity, knee surgery, unilateral, and bilateral knees involved, etc. will affect the pain, physical, and functional status of the patients. Knee osteoarthritis also affects adults in some cases. So, we aimed to assess the outcomes of knee osteoarthritis using the Knee Injury and Osteoarthritis Outcome Score (KOOS) scale. Knee Injury and Osteoarthritis Outcome Score (KOOS) scale was a disease-specific, reliable, validated, and standardized instrument for measuring knee osteoarthritis outcomes using five domains: pain, symptom, activities of daily living, sports and recreation, and quality of life [8]. It can be easily administered, takes only 10 minutes to complete.

How to cite this article: Mugada Vinodkumar, Kondru Pujitha, Manda Sai Navya, Vegi Mahalakshmi, Kakada Smruthi. Assessment of patient relevant outcomes in knee osteoarthritis patients using the Knee Injury and Osteoarthritis Outcome Score (KOOS) scale. J Res Pharm. 2020; 24(5): 786-792. 


\section{RESULTS}

Table 1. Association of sociodemographic characteristics of patients with respect to different domains of Knee Injury and Osteoarthritis Outcome Score (KOOS) scale.

\begin{tabular}{|c|c|c|c|c|c|c|}
\hline Characteristic & Freq $(\%)$ & $\begin{array}{c}\text { Pain } \\
\text { p-value }\end{array}$ & $\begin{array}{c}\text { Symptom } \\
\text { p-value }\end{array}$ & $\begin{array}{c}\text { ADL } \\
\text { p-value }\end{array}$ & $\begin{array}{c}\text { Sports/Rec } \\
\text { p-value }\end{array}$ & $\begin{array}{c}\text { QoL } \\
\text { p-value }\end{array}$ \\
\hline \multicolumn{7}{|l|}{ Age in years $\S$} \\
\hline $30-40$ & $20(16.66)$ & 0.715 & 0.778 & 0.697 & 0.973 & 0.373 \\
\hline $41-50$ & $45(37.50)$ & & & & & \\
\hline $51-60$ & $55(45.83)$ & & & & & \\
\hline \multicolumn{7}{|l|}{ Gender } \\
\hline Male & $28(23.33)$ & & & & & \\
\hline Female & $92(76.67)$ & 0.095 & $0.038^{*}$ & 0.401 & 0.294 & $0.011^{*}$ \\
\hline \multicolumn{7}{|l|}{ Comorbidities $\sharp$} \\
\hline Yes & $51(42.50)$ & 0.125 & $0.022^{*}$ & 0.064 & 0.448 & 0.389 \\
\hline No & $69(57.50)$ & & & & & \\
\hline \multicolumn{7}{|l|}{ Knee Surgery } \\
\hline Yes & $8(6.67)$ & & & & & \\
\hline No & $112(93.33)$ & 0.163 & 0.500 & $0.043^{*}$ & 0.054 & 0.344 \\
\hline \multicolumn{7}{|l|}{ Knee Involved§ } \\
\hline Right & $22(18.33)$ & & & & & \\
\hline Left & $25(20.83)$ & 0.398 & 0.634 & 0.088 & $0.031^{*}$ & 0.621 \\
\hline Both & $73(60.83)$ & & & & & \\
\hline \multicolumn{7}{|c|}{ Body Mass Index $\$$} \\
\hline Underweight & $6(5.0)$ & & & & & \\
\hline Normal weight & $69(57.50)$ & 0.135 & $0.017^{*}$ & 0.064 & 0.376 & 0.844 \\
\hline Overweight & $31(25.83)$ & & & & & \\
\hline Obese & 14(11.67) & & & & & \\
\hline \multicolumn{7}{|c|}{ Socio Economic Status $§$} \\
\hline Grade II & $3(2.50)$ & & & & & \\
\hline Grade III & $20(16.67)$ & 0.239 & 0.503 & 0.303 & 0.668 & 0.623 \\
\hline Grade IV & $43(35.83)$ & & & & & \\
\hline Grade V & $54(45.00)$ & & & & & \\
\hline \multicolumn{7}{|c|}{ Disease Durations } \\
\hline 1-12 months & $72(60.00)$ & & & & & \\
\hline 13-24 months & $26(21.77)$ & $0.031^{*}$ & 0.404 & 0.276 & $0.033^{*}$ & 0.109 \\
\hline$>24$ months & $22(18.33)$ & & & & & \\
\hline
\end{tabular}

" $\mathrm{p}<0.05$ was statistically significant. ADL= Activities of Daily Living; Freq= Frequency; Rec= Recreation; QoL= Quality of Life; $\mathbf{q}=$ independent samples-t-test; $\S=$ ANOVA test

The mean age of patients in our study was $54.58 \pm 10.73$ years. Age group between $51-60$ years are more commonly affected $(45.83 \%)$. Females $(76.67 \%)$ were higher than males. Patients with comorbidities $(57.50 \%)$, no knee surgery (93.33\%), both knees involved (60.83), normal weight $(57.50 \%)$, and disease duration between 1-12 months (60\%) were high in number (Table 1). Statistically significant association was observed between pain and disease duration; symptom and gender, comorbidities, body mass index; activities of daily living and knee surgery; sports/recreation and knee involved, disease duration; and knee related quality of life and gender (Table 1).

Table 2 provides summary measures of all quantitative data and domains of the KOOS questionnaire. The mean disease duration was $15.34 \pm 13.67$ months. The mean body mass index was $24.43 \pm 4.04$. The mean scores of domains were less than the average score of 50 and indicates moderate problems. The sports/ recreation mean score was below 15 , indicates severe problem.

Statistically significant positive correlation was observed between symptom and comorbidities. Statistically significant negative correlation was observed between sports/recreation and no. of knees involved, knee surgery. Statistically highly significant negative correlation was observed between subscale pain and knee surgery, activities of daily living and knee surgery (Table 3). Figure 1 illustrates correlational matrix of different KOOS domains. Statistically highly significant positive correlation $(p<0.01)$ was observed between different domains. 
Table 2. Summary measures of some sociodemographic variables and Knee Injury and Osteoarthritis Outcome Score (KOOS) domains.

\begin{tabular}{lcc}
\hline Name of the variable/domain & $\begin{array}{c}\text { Mean (Standard } \\
\text { Deviation) }\end{array}$ & Minimum- Maximum \\
\hline Age & $54.58(10.73)$ & $30-70$ \\
Disease Duration & $15.34(13.67)$ & $1-48$ \\
Body Mass Index & $24.43(4.04)$ & $16.8-37.1$ \\
Pain & $41.12(18.78)$ & $3-84$ \\
Symptom & $49.33(20.51)$ & $11-96$ \\
Activities of Daily Living & $41.57(18.55)$ & $2-89$ \\
Sports/ Recreation & $11.97(12.27)$ & $0-42$ \\
Quality of Life & $39.42(15.68)$ & $13-81$ \\
\hline
\end{tabular}

Table 3. Correlation of sociodemographic variables with Knee Injury and Osteoarthritis Outcome Score (KOOS) domains.

\begin{tabular}{llll}
\hline Name of the variable & Name of the KOOS domain & r-value & p-value \\
\hline No. of knees involved & Sports/Recreation & -0.19 & $0.021^{*}$ \\
Knee Surgery ${ }^{\dagger}$ & Pain & -0.28 & $0.000^{* *}$ \\
& Symptom & -0.20 & $0.013^{*}$ \\
& Activities of daily living & -0.30 & $0.000^{* *}$ \\
& Sports/ Recreation & -0.16 & $0.043^{*}$ \\
Comorbidities $^{\dagger}$ & Symptom & 0.17 & $0.029^{*}$ \\
\hline
\end{tabular}

${ }^{*} \mathrm{p}<0.05$ statistically significant; ${ }^{* *} \mathrm{p}<0.01$ statistically highly significant; $\dagger=$ Spearman's Correlation

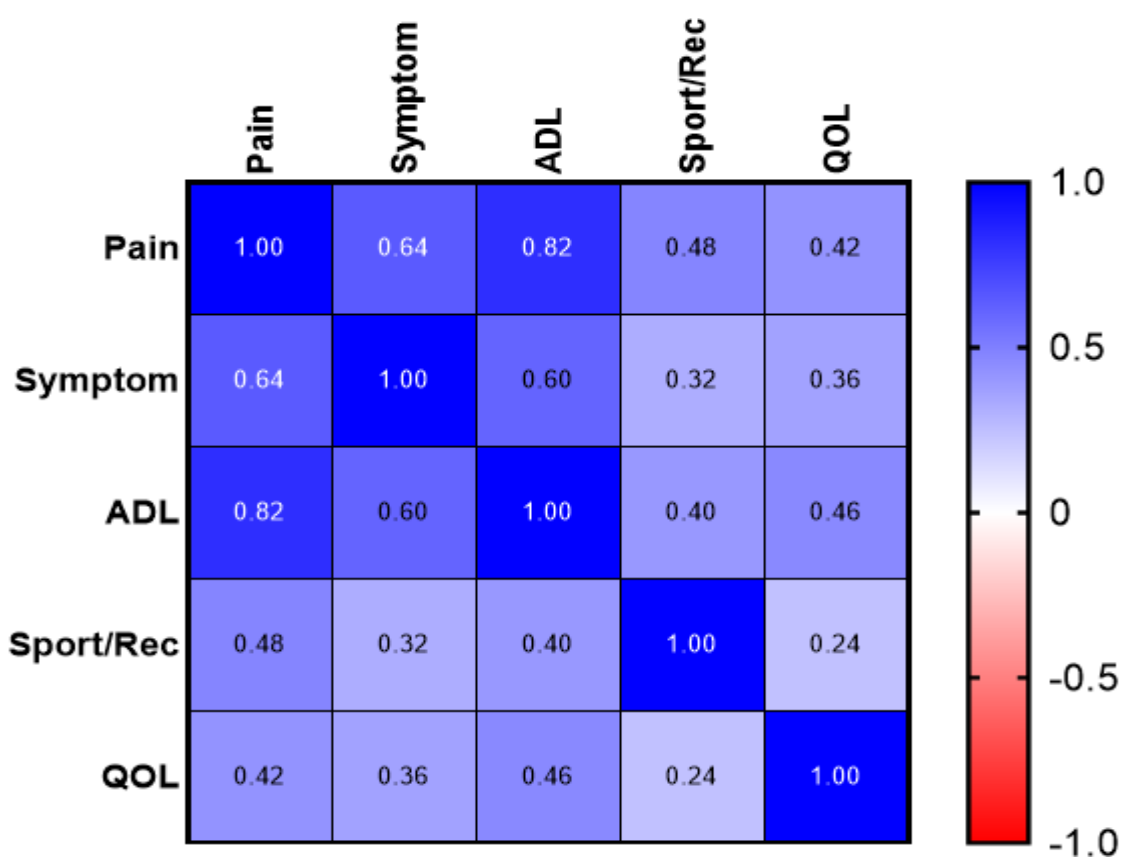

Figure 1. Correlation matrix of Knee Injury and Osteoarthritis Outcome Score (KOOS) subscales.

Each value in the matrix represents the Pearson Correlation coefficient. Each positive value indicates positive correlation.

The legend on the right side indicates the correlation coefficient range from -1.0 to +1.0 . There was statistically highly significant positive correlation $(\mathrm{p}<0.0001)$ between the KOOS subscales. ADL= Activities of Daily Living, Rec $=$ Recreation, $\mathrm{QOL}=$ Quality of Life 


\section{DISCUSSION}

The mean age of patients was $54.58 \pm 10.73$ years. Females were more commonly affected than males in our study. Aging increases the chances of osteoarthritis with varying severity. However, joint injury or repeated joint stress can predispose adults to get osteoarthritis. Over age 50 years, women are affected by osteoarthritis than men [9]. Postmenopausal women reported severe knee pain. A comparative analysis in Latin America on the characterization of knee osteoarthritis reported a mean age of $61.8 \pm 12$ years, and females were majorly affected $(80.8 \%)$. The mean age group varied between countries Argentina ( $65 \pm 10$ years), Brazil ( $57 \pm 12$ years), and Mexico (61 \pm 11 years). The females were the most commonly affected in all three countries [10]. A cross-sectional study by Cubukcu et al. [11] in Turkey reported a mean age group of 56.98 \pm 8.28 , and females are commonly affected than males (86.8\%). In a study by Narayan et al. [12] in southern India, a mean age group of $55.7 \pm 8.8$ years was reported. Knee pain also has an impact on the knee-related quality of life in the patients.

Bindawas et al. [13] reported a lower score of knee-related quality of life on the KOOS scale in frequent bilateral knee pain than unilateral or no pain patients. In our study, there was a statistically significant association between the number of knees involved and the problem with sports/recreation. Also, there was a statistically significant negative correlation between the number of knees involved and the sports/recreation subscale of KOOS.

The mean body mass index was $24.43 \pm 4.04$. Our study observed a significant association of body mass index with symptom subscale $(\mathrm{p}=0.017)$. Obesity was associated with joint pain, increased incidence, and progression of osteoarthritis [14]. A study by Elsoe et al. [15] reported a mean body mass index of 48.3, and obese patients reported significantly worse in the subscales of pain, activities of daily living, sport, and quality of life. Edwards et al. [16] compared KOOS scores for patients at baseline and at 6 and 12 months post-bariatric surgery for weight loss and observed a significant improvement $(\mathrm{p}<0.05)$ in all the subscales of the KOOS.

The mean score of sports/ recreation subscale indicates severe problems, whereas other subscales indicate moderate problems in those respective areas. During interaction with patients, they expressed their problems and some common reasons for them. Most of the patients reported difficulty while standing up after sitting some time, climbing up and getting down the stairs, getting on/off the toilet. Most people experience severe pain while ascending the stairs. Patients who lifted heavy weights and engaged in heavy domestic duties reported severe knee pain.

The socioeconomic status of patients plays a crucial role in the affordability of medicines. Some of our subjects were poor, unable to afford better medicines, and depend only on pain killer medications. A fixeddose combination of calcitriol $0.25 \mathrm{mg}$, elemental calcium $500 \mathrm{mg}$, elemental zinc $20 \mathrm{mg}$, and ibandronate acid $150 \mathrm{mg}$ will be advised for only those patients who can afford it. It was expensive for grade IV and V status patients. Patients with severe osteoarthritis cannot go for knee replacement surgery due to poor financial status. Financial status also prone subjects to malnourishment, causing low levels of calcium, which further increases osteoarthritis. Negligence of symptoms and self-medication using pain killers lead to worsening of osteoarthritis in some patients. They did not visit the hospital during the early stages and used OTC medications to manage their pain. Eventually, it led to disease progression. Many patients, due to negligence, did not change their lifestyle even after a suggestion from the physician, and it led to potential damage to the knees.

Non-adherence of patients-missed follow-ups, not following lifestyle modifications like weight loss, forgetfulness to take medications, contributed to worsening of osteoarthritis. In contrast, people having regular follow-ups, adherence to medication, and course of treatment reported less pain and can do their daily activities actively. However, they reported that they can control their symptoms when they are on medication, and their symptoms used to recur after they stop medications. Some elderly patients reported that lack of awareness about disease progression; they neglected follow-ups and thought that one-time use of medicines would cure the knee pain.

Lower body positive pressure (LBPP) was a low-load walking exercise on the treadmill, which has promising results. It is a safe and user-friendly form of weight-bearing exercise for the progressive knee osteoarthritis or those at risk of developing or exacerbating knee osteoarthritis symptoms due to obesity [17]. Peeler et al. [17] observed a significant improvement in pain subscale, while a highly significant improvement in all other subscale scores of KOOS using LBPP. He concluded that LBPP could be successfully used to diminish joint pain, enhance joint function, and increase thigh muscle strength in even most at-risk obese patients with knee osteoarthritis. The intra-articular hyaluronic acid injection is also one option for knee osteoarthritis. Bowman et al. [18] reported an improvement in mean subscales of KOOS domains from baseline 
to follow-up (an average of 27 months) in patients who showed positive response for first injection, mild to moderate osteoarthritis (grades 1-2).

Knee surgery had a statistically highly significant negative correlation with pain and activities of the daily living subscale. Patients who underwent knee surgery are very low because the total knee arthroplasty was so expensive, and nearly $80 \%$ of patients cannot afford it due to their low economic status (Table 1). Upon Multiple linear regression analysis, knee surgery was found to be the independent predictor for pain $(\mathrm{p}=0.008)$ and activities of daily living $(\mathrm{p}=0.008)$. Subscale symptoms had a statistically significant positive correlation with comorbidities. In our study, few patients with hypertension, diabetes, and hypothyroidism reported severe knee pain and knee swelling. A statistically highly significant positive correlation $(p<0.0001)$ was observed between different KOOS subscales.

Our study had a few limitations. Due to time constraints and patient-related factors, we were unable to follow-up. In the hospital, there is no facility for knee arthroplasty on a non-profit basis. However, they will perform knee replacement surgery for all the eligible patients for free. As the sample size was small, we cannot generalize the study results to all the elderly patients suffering from knee osteoarthritis.

\section{CONCLUSION}

There was a severe problem with sports/recreation in the patients. The knee related quality of life was moderate. Knee surgery was found to be an independent predictor for pain and activities of daily living. However, socioeconomic status influenced the knee surgery in our patients.

\section{MATERIALS AND METHODS}

\subsection{Study site, study duration, study design}

A descriptive cross-sectional study was conducted at Department of Orthopaedics, Visakha Institute of Medical Sciences, Hanumanthuwaka for a duration of six months (01/08/2019 to 31/01/2020).

\subsection{Sample size and sampling technique}

The estimated sample size was 115 (estimated margin of error was $6 \%$, the confidence interval was 95\%, population size was 200, and response distribution was 50\%). Simple random sampling was used to select individuals.

\subsection{Study participants}

Patients with age group between 30-70 years with symptoms of knee osteoarthritis of both gender, patients with primary and secondary osteoarthritis, and patients who are willing to cooperate were included in the study. Patients with $>70$ years and $<30$ years of the age group who can't spare the time were excluded from the study.

\subsection{Study instruments}

The Knee Injury and Osteoarthritis Outcome Score (KOOS) scale were used to assess short and longterm patient-relevant outcomes following a knee injury. It assesses five issues: pain, symptoms, activities of daily living, sports and recreation function, and knee-related quality of life. It also used to evaluate the course of knee injury and treatment outcome. All items have five answer options scored from 0 (None) to 4 (extreme problems). Scores are transformed to a 0-100 scale, with zero representing severe knee problems and 100 representing no knee problems [8]. The questionnaire and scoring manual can be accessed freely from the website http://www.koos.nu. For convenience we used telugu version of KOOS scale from this website. Socioeconomic status of the patients was calculated using Modified Kuppuswamy Socioeconomic status scale.

\subsection{Ethical committee approval}

The study was approved by the Institutional Human Ethics Committee (VIPT/IEC/62/2019).

\subsection{Data collection}

The aims and objectives of our research study were clearly explained for the patients. We obtained written patient informed consent from patients who expressed their interest in participating in the study. A prestructured data collection form was prepared for the study. Details like age, gender, socioeconomic status, 
knee surgery, knee involved, comorbidities, height, and weight for calculating body mass index, duration of disease was collected. Every patient was interviewed for KOOS scale.

\subsection{Data analysis}

The normality of the data was assessed using Shapiro Wilk test. If the data follows normality then mean and standard deviation was calculated to describe the data, otherwise, median and inter quartile range was used to describe the data. Parametric tests like independent samples-t-test for two groups and ANOVA for three groups was calculated for data with normality. Non-parametric tests like Mann-Whitney test for two groups and Kruskal-Wallis test for three groups was calculated. Pearson's correlational analysis was used for quantitative variables, whereas, Spearman's correlation analysis was used for categorical variables like comorbidities and knee surgery. The level of significance was considered at $\mathrm{p}<0.05$, a high statistical significance at $\mathrm{p}<0.01$. Multiple linear regression analysis was used to find the predictors for subscales of KOOS questionnaire. Minitab version 18.0 was used to perform statistical analysis. Graph Pad Prism version 8.4.1 was used to represent correlational matrix (heat map) using Pearson correlation between different domains of KOOS scale.

Acknowledgements: We are grateful for Dr. Ewa. M. Roos, Professor of Musculoskeletal Function and Physiotherapy, Southern Denmark University, for answering our queries regarding KOOS scale. We are grateful for Dr. K.Rajani Kumar, Department of Orthopedics, Visakha Institute of Medical Sciences for his support and guidance throughout our research study.

Author contributions: Concept - VK.M., P.K., S.N.M.; Design -VK.M.; Supervision -VK.M.; Resources -P.K., S.N.M., S.K., M.V.; Materials - P.K., S.N.M., S.K., M.V.; Data Collection and/or Processing - P.K., S.N.M., S.K., M.V.; Analysis and/or Interpretation - VK.M. Literature Search - P.K., S.N.M., S.K., M.V.; Writing -VK.M.; Critical Reviews - VK.M., P.K., S.N.M., S.K., M.V.

Conflict of interest statement: The authors declare no conflict of interest.

Ethics committee approval: This study was approved by the Institutional Human Ethics Committee with the number of VIPT/IEC/62/2019 on July 24, 2019.

\section{REFERENCES}

[1] White DK, Tudor-Locke C, Zhang Y, Fielding R, LaValley M, Felson DT, Gross KD, Nevitt MC, Lewis CE, Torner J, Neogi T. Daily walking and the risk of incident functional limitation in knee osteoarthritis: an observational study. Arthritis Care Res (Hoboken). 2014;66(9);1328-1336. [CrossRef]

[2] White DK, Lee J, Song J, Chang RW, Dunlop D. Potential functional benefit from light intensity physical activity in knee osteoarthritis. Am J Prev Med. 2017; 53(5):289-296. [CrossRef]

[3] Dunlop DD, Song J, Lee J, Gilbert AL, Semanik PA, Ehrlich-Jones L, Pellegrini CA, Pinto D, Ainsworth B, Chang RW. Physical Activity Minimum Threshold Predicting Improved Function in Adults with Lower-Extremity Symptoms. Arthritis Care Res (Hoboken). 2017; 69(4): 475-483. [CrossRef]

[4] Cross M, Smith E, Hoy D, Nolte S, Ackerman I, Fransen M, Bridgett L, Williams S, Guillemin F, Hill CL, Laslett LL, Jones G, Cicuttini F, Osborne R, Vos T, Buchbinder R, Woolf A, March L. The global burden of hip and knee osteoarthritis: estimates from the global burden of disease 2010 study. Ann Rheum Dis. 2014; 73(7): 1323-1330. [CrossRef]

[5] Pal CP, Singh P, Chaturvedi S, Pruthi KK, Vij A. Epidemiology of knee osteoarthritis in India and related factors. Indian J Orthop. 2016; 50(5): 518-522.

[6] Evcik D, Sonel B. Effectiveness of a home-based exercise therapy and walking program on osteoarthritis of the knee. Rheumatol Int. 2002; 22(3):103-106. [CrossRef]

[7] Sabirli F, Paker N, Bugdayci D. The relationship between Knee Injury and Osteoarthritis Outcome Score (KOOS) and Timed Up and Go test in patients with symptomatic knee osteoarthritis. Rheumatol Int. 2013; 33(10):2691-2694. [CrossRef]

[8] Roos EM, Roos HP, Lohmander LS, Ekdahl C, Beynnon BD. Knee Injury and Osteoarthritis Outcome Score (KOOS)development of a self-administered outcome measure. J Orthop Sports Phys Ther. 1998; 28(2):88-96. [CrossRef]

[9] The Basics of Osteoarthritis 2020. https://www.webmd.com/osteoarthritis/guide/osteoarthritis-basics\#1 (accessed 11th April 2020). 
[10] Burgos-Vargas R, Cardiel MH, Loyola-Sanchez A, De Abreu MM, Pons-Estel BA, Rossignol M, Avouac B, Ferraz MB, Halhol H. Characterization of knee osteoarthritis in Latin America. A comparative analysis of clinical and health care utilization in Argentina, Brazil, and Mexico. Reumatol Clin. 2014; 10(3): 152-159. [CrossRef]

[11] Cubukcu D, Sarsan A, Alkan H. Relationships between Pain, Function, and Radiographic Findings in Osteoarthritis of the knee: A cross sectional study. Arthritis. 2012; 2012: 984060. [CrossRef]

[12] Narayan RV, Thabah MM, Poduval M. Neuropathic pain among patients with primary knee osteoarthritis- results of a cross sectional study from a tertiary care centre in Southern India. Indian J Rheumatol. 2017; 12(3): 132-138. [CrossRef]

[13] Bindawas S, Vishal V, Soham AS. Differences in Health-Related Quality of Life among Subjects with Frequent Bilateral or Unilateral Knee Pain: Data from the Osteoarthritis Initiative Study. J Orthop Sports Phys Ther. 2015; 45(2): 128-136. [CrossRef]

[14] Kulkarni K, Karssiens T, Kumar V, Pandit H. Obesity and osteoarthritis. Maturitas. 2016; 89: 22-28. [CrossRef]

[15] Larsen P, Engberg AS, Motahar I, Ostgaard SE, Elsoe R. Obesity infleunces the Knee Injury and Osteoarthritis Outcome Score. Joints. 2019; 7:8-12. [CrossRef]

[16] Edwards C, Rogers A, Lynch S, Pylawka T, Silvis M, Chinchilli V, Mosher T, Black K. The effects of bariatric surgery weight loss on knee pain in patients with osteoarthritis of the knee. Arthritis. 2012; 2012:504189. [CrossRef]

[17] Peeler J, Christian M, Cooper J, Leiter J, MacDonald P. Managing Knee Osteoarthritis: The Effects of Body Weight Supported Physical Activity on Joint Pain, Function, and Thigh Muscle Strength. Clin J Sport Med. 2015; 25(6):518523.

[18] Bowman EN, Hallock JD, Throckmorton TW, Azar FM. Hyaluronic acid injections for osteoarthritis of the knee: predictors of successful treatment. Int Orthop. 2018; 42(4): 733-740. [CrossRef]

This is an open access article which is publicly available on our journal's website under Institutional Repository at http://dspace.marmara.edu.tr. 